\title{
COMPREENSÃO SOBRE AADOÇÃO POR CASAIS HOMOAFETIVOS SEGUNDO OS PROFISSIONAIS QUE ATUAM NESSES PROCEDIMENTOS: UM ESTUDO EXPLORATÓRIO
}

MASTROIANNI , Fábio de Carvalho. Psicólogo judiciário do Tribunal de Justiça do Estado de São Paulo e professor do curso de Psicologia e de Direito do Centro Universitário de Araraquara - UNIARA.

E-mail: psicomastroianni@gmail.com.

LIMA, Gabriela Schmidt de; MELLO, Patrícia Cristina Rodrigues; FERREIRA, Thaluane Jaice Estrela.

Psicólogas formadas pelo Centro Universitário de Araraquara - UNIARA.

\section{RESUMO}

A legislação brasileira que regulariza a união estável e o casamento entre homossexuais é recente equestões relacionadas ao tema ainda geram discussões. O objetivo desta pesquisa foi explorar a compreensão de psicólogos e assistentes sociais que atuam em processos de adoção sobre essa nova possibilidade. Realizou-se uma pesquisa de cunho qualitativo junto a esses profissionais, utilizando-se um roteiro de entrevista semiestruturado, onde as respostas foram analisadas através da técnica denominada análise de conteúdo. A amostra foi composta por 7 (sete) indivíduos, todos do sexo feminino, com formação nas respectivas áreas. Mesmo não relatando experiência direta com a adoção por casal homoafetivo, as participantes descreveram situações em que se depararam com essa dinâmica de relacionamento em processos de outra natureza que não a adoção conjunta, permitindo explorar a compreensão delas sobre o assunto. Verifica-se que a adoção por si só já envolve mitos e preconceitos, mas as profissionais se sentem preparadas e satisfeitas em atuar nesses procedimentos. O mesmo, entretanto, não se observa com a adoção realizada por casais homoafetivos, tendo elas reconhecido a necessidade de maior preparo e reflexão para atuar nesses processos. Trata-se de um estudo exploratório que se limita a abordar um pequeno grupo de indivíduos do universo de profissionais que atuam nesses procedimentos. Embora não permita realizar considerações mais abrangentes, pretende apresentar subsídios para uma discussão inicial.

Palavras-chave: Adoção; Casais homoafetivos; Análise de conteúdo; Pesquisa qualitativa.

UNDERSTANDING ADOPTION BY HOMOSEXUAL PAIRS ACCORDING TO THE PROFESSIONALS ACTING IN THESE PROCEDURES: AN EXPLORATORY STUDY

\begin{abstract}
The Brazilian legislation that regularizes stable union and the marriage between homosexuals is recent and matters related to this theme still generate discussions. The aim of this paper was to explore the understanding of psychologists and social workers that act in adoption processes about this new possibility. Aqualitative research was developed with these professionals, by means of a semi-structured interview, and the answers were analyzed using the content analysis technique. The sample was formed by 7 (seven) individuals, all of the feminine sex, with professional education in their respective areas. The participants, even reporting no direct experience with adoption by homosexual pairs, described situations which they came across with this type of relationship in processes of another nature, different from joint adoption, allowing them to explore their comprehension about the subject. It was verified that adoption itself already involves myths and prejudices, but the professionals feel ready and satisfied in acting in these procedures. The same, however, isn't observed in the adoptionby homosexual couples, having recognized their necessity of a greater prepare and reflection to act in these processes. It is an
\end{abstract}


exploratory study which is limited to a small group of individuals of the universe of professionals who act in these procedures. Although this study doesn't allow us to offer more comprehensive considerations about this subject, it intends to present subsidies for an initial discussion.

KeYwords: Adoption; Homosexual pairs; Content analysis; Qualitative research.

\section{INTRODUÇÃO}

A adoção de crianças e jovens por casais do mesmo gênero tem sido assunto bastante discutido pela imprensa, população e os operadores de direito de modo geral. Com a aprovação do Ofício $\mathrm{n}^{\circ}$. 81/PMC de 2011, que regulamenta a união entre homossexuais, e mais recentemente com a resolução $\mathrm{n}^{\mathrm{o}} 175$, de 14 de maio de 2013, do Conselho Nacional de Justiça, que obriga a todos os cartórios do país a celebrar casamentos entre pessoas do mesmo sexo, a convivência entre casais homoafetivos, em termos de direitos compartilhados, passou a ser reconhecida. Mesmo atendendo aos interesses de uma parcela da população, a regulamentação e a resolução não impediram que divergências e discussões a respeito do tema pudessem surgir, principalmente quando se pondera a possibilidade de essas pessoas assumirem, através da adoção e de forma conjunta, os papéis parentais.

Futino e Martins (2006) e Costa (2003) perceberam, em suas revisões sobre o tema, que ao longo da história algumas teorias foram construídas para tentar explicar a homossexualidade, desde aquelas que atribuem sua constituição a aspectos hereditários ou a defeitos congênitos, associando, portanto, o surgimento de transtornos mentais à orientação sexual dos indivíduos, até as que consideram a interação de aspectos biológicos e sociais. Segundo os autores, essas últimas têm sido mais utilizadas atualmente e, diferente das anteriores, não relacionam enfermidade com orientação sexual, pelo contrário, enfatizam a discriminação e a repressão social pela qual esses indivíduos geralmente são submetidos como um dos principais fatores de risco para o desenvolvimento de morbidades psiquiátricas.

Sob esse novo paradigma, os indivíduos homossexuais deixam de se ocultar e passam a se autodenominar "gays". O termo "homossexualismo" deixou de ser utilizado, uma vez que o sufixo "ismo", na cultura médica, indicava "doença", sendo, portanto, substituído pela denominação homossexualidade, onde o sufixo "dade" relaciona-se a "modo de ser" e não a uma condição clínica (COSTA, 2003; FUTINO; MARTINS, 2006). Homossexualidade, deste modo, não se restringe à atividade sexual, podendo-se, em um sentido mais amplo, utilizar-se o termo para descrever o desejo de um sujeito em se vincular emocionalmente e conviver com outra pessoa do mesmo sexo (CHEMIN; SESARINO, 2007).

Se, ao longo dos anos, a forma como a sociedade lidou com os homossexuais passou por algumas transformações, o mesmo se observa em relação ao modo como a instituição familiar foi assumindo novas configurações. Inicialmente, coma regulamentação do primeiro Código Civil, em 1916, a constituição de um grupo familiar no Brasil só era juridicamente reconhecida através do matrimônio entre um homem e uma mulher. Ambos tinham papéis bem definidos, cabendo ao primeiro o poder e a autoridade familiar, enquanto os cuidados da prole ficavam sob a responsabilidade de suas esposas (PRATTA; SANTOS, 2007). Amazonas et al. (2003), em um estudo que investigou os arranjos familiares e as formas de funcionamento das famílias de crianças de uma escola pública da cidade do Recife, destacaram que novas configurações familiares passaram a surgir no Brasil desde as transformações ocorridas em meados dos anos 60, com o ingresso da mulher no mercado de trabalho, controle de natalidade e maior liberdade sexual, entre outras.

Distintas do modelo tradicional, essas novas formações - constituídas por famílias monoparentais e uniões afetivas sem matrimônio ou por casais divorciados - só foram reconhecidas na "Constituição Federal" de 1988. Por meio do novo direcionamento político, a família passou a receber maior atenção do 
Estado, devendo este responsabilizar-se pela sua proteção, bem como promover recursos para o seu desenvolvimento (Art. 226, $\S 3^{\circ}, \S 4^{\circ}, \S 7^{\circ}$ ). Ao regular a possibilidade de outras configurações, o conceito de família também foi ampliado, enfatizando-se, a partir daí, a importância dos laços afetivos em detrimento dos casamentos e relações consanguíneas (COSTA, 2003; SALOMÉ; ESPÓSITO; MORAES, 2007).

A finalidade voltada à procriação ou geração de filhos deixa de ser o atributo principal das famílias e, nesse sentido, as trocas afetivas, o respeito e a necessidade de servir como modelo de referência aos seus membros passam a ser as principais funções dos familiares, os quais devem enfatizar o cuidado e o desenvolvimento de crianças e jovens (CHEMIN; SESARINO, 2007; FUTINO; MARTINS, 2006; SALOMÉ; ESPÓSITO; MORAES, 2007). Com essas transformações, o papel anteriormente atribuído ao gênero, à genética e à orientação sexual dos pais foi perdendo cada vez mais a sua importância, permitindo-se, no contexto atual, definir família como uma relação socioafetiva (PAULO, 2009).

A adoção, portanto, é um exemplo de constituição familiar que se dá apenas em relação aos vínculos afetivos, uma prática que há muito tempo já se observava nas mais primitivas sociedades, mesmo antes de haver qualquer regulamentação a respeito (SILVA, 2009; SOUZA, 2008; SOUZA; MIRANDA, 2007; WEBER, 2004, 2001). Nessa situação de mudança, em que novos arranjos familiares passam a permitir outras possibilidades de relacionamento, é que surge a adoção por casais homoafetivos, uma modalidade que, mesmo sem nenhuma regulamentação anterior, já era observada em alguns contextos sociais. Ao reconhecer essas configurações, a legislação não está promovendo novos arranjos, mas sim acompanhando as transformações que ocorrem na dinâmica de relacionamentos entre os indivíduos (CHEMIN; SESARINO, 2007; FUTINO; MARTINS, 2006; SALOMÉ; ESPÓSITO; MORAES, 2007).

A adoção deverá ser deferida apenas se o ato proporcionar reais vantagens à criança e/ou adolescente, fundando-se, portanto, em motivos legítimos que favorecerão o desenvolvimento infantil. O Estatuto da Criança e do Adolescente (Lei 8.069/ 1990) concede a adoção apenas para indivíduos maiores de 18 (dezoito) anos, independentemente do estado civil, desde que possuam pelo menos 16 (dezesseis) anos a mais que o adotando. Para a adoção conjunta é indispensável que os adotantes sejam casados civilmente ou mantenham união estável, comprovada a estabilidade (Art. 42, § 2, § 3).

Recentes pesquisas no campo da adoção homoafetiva, citadas nos estudos de Paulo (2009) e Futino e Martins (2006), apontam que crianças cujos pais possuem o mesmo sexo podem ser tão ajustadas quanto as crianças com pais de sexos diferentes. Em sua revisão, os autores mostram que diversas associações americanas (de psicólogos, pediatras, psiquiatras e psicanalítica) já se pronunciaram sobre o tema, afirmando que pais homossexuais podem ser tão capazes de proporcionar ambientes saudáveis e protetores aos seus filhos quanto os casais heteroafetivos. Além disso, não apontam diferenças em relação ao desenvolvimento emocional, cognitivo, social e sexual dessas crianças ou jovens por se desenvolverem nesses lares.

As recentes mudanças ocorridas na legislação permitiram que casais homoafetivos pudessem requerer e se inscrever em cadastros de pretendentes à adoção. É válido destacar que, mesmo anteriormente (Lei n. 8069/1990), já não havia impedimentos para indivíduos com orientação homossexual, mas, como a lei só permitia a adoção conjunta por membros que formassem uma família (juridicamente reconhecida), a adoção por esses indivíduos só podia ocorrer de forma unilateral. Nesse sentido, concluem os autores que os impedimentos e controvérsias ainda existentes se referem a questões morais, reflexo de uma sociedade que, embora esteja mudando seus conceitos e valores, ainda o faz lentamente (FERNÁNDEZ; VILAR, 2004 apud FUTINO; MARTINS, 2006).

Para Futino e Martins (2006), os argumentos utilizados pelos juízes, visando impossibilitar aos pares homoafetivos o direito à filiação, foram historicamente construídos em nossa sociedade. Essas ideias, 


\section{MASTROIANNI et al.}

entretanto, atualmente vêm perdendo intensidade quando confrontadas com as teorias da paternidade socioafetiva e do apego, que não associam a orientação sexual com a capacidade de desempenhar as funções parentais. Para as autoras, é necessário questionar as competências de alguns juízes e peritos envolvidos nessa avaliação. Uma das argumentações para o indeferimento da adoção por indivíduos homossexuais relaciona-se ao estabelecimento de papéis.

O senso comum tende a defender a importância do modelo pai e mãe no desenvolvimento da criança, atribuindo à mãe a função de cuidadora e ao pai o papel normatizador. Futino e Martins (2006) consideram o raciocínio um equívoco, uma vez que as atribuições de gênero em nossa sociedade não são prédefinidas ou relacionadas apenas à genética; assim como algumas crenças, tais atribuições também foram socialmente construídas. Araújo et al. (2007) consideram que a adoção de infantes por casais homoafetivos concerne uma atitude inclusiva, haja vista que a prioridade no processo de adoção é o bemestar geral da criança, o que independe, segundo os autores, da orientação sexual dos adotantes.

Nesse sentido, o mais importante, independente da orientação sexual, é que os pretendentes à adoção estejam preparados para as adversidades e os desafios inerentes ao tema. Os candidatos precisam ser trabalhados de forma preventiva, cabendo aos profissionais responsáveis pela avaliação e preparação auxiliá-los a elaborar suas próprias dificuldades e resistências, ajudando-os a construir uma identidade parental que permita uma vinculação mais adequada com a futura criança ou adolescente. Torna-se, portanto, necessário abordar as expectativas, responsabilidades, motivações e a dinâmica dos requerentes à adoção (SCHETTINI; AMAZONAS; DIAS, 2006; SOUZA; MIRANDA, 2007).

A adoção, portanto se configura e um encontro entre partes distintas que necessitam elaborar alguns aspectos psicossociais relacionados ao tema, e é papel da equipe técnica (psicólogos, assistentes sociais ou outros profissionais) favorecer e facilitar essa conjunção (COSTA; CAMPOS, 2003). Ao ingressarem com o requerimento de inscrição no cadastro de pessoas habilitadas à adoção, os postulantes são submetidos às avaliações realizadas pelos profissionais da equipe técnica, os quais, através de seus laudos, oferecerão subsídios ao juiz para o deferimento ou não do pedido. Além da avaliação junto aos postulantes, as equipes técnicas também devem se atentar às necessidades das crianças que serão colocadas em família substituta, analisando aspectos de adaptação e aceitação, sem olvidar a história de sofrimento e abandono dessas crianças e adolescentes (SOUZA, 2008; WEBER, 2004).

Essa preparação se mostra mais indicada quando realizada em conjunto com os profissionais da instituição de acolhimento e das equipes técnicas, ambas geralmente formadas por psicólogos e assistentes sociais. Tais equipes, cada qual em seu âmbito, devem trabalhar com as famílias interessadas os aspectos referentes ao histórico de abandono desses infantes, bem como as particularidades e as demandas de cada um (SOUZA; MIRANDA, 2007). Desse modo, considerando que psicólogos e assistentes sociais são importantes personagens dentro dos procedimentos de adoção (tanto na avaliação dos postulantes quanto na efetivação da adoção e aproximação entre as famílias e as crianças/jovens), torna-se importante explorar como eles compreendem a atuação profissional quando o requerimento é realizado por casais homoafetivos.

Nesse sentido, o presente estudo teve por finalidade: explorar a compreensão de psicólogos e assistentes sociais que atuam em procedimentos de adoção acerca da adoção por casais homoafetivo, se observam riscos, contraindicações ou cuidados específicos com processos dessa natureza, e verificar como se sentem para atuar com essas demandas.

\section{Método}

\section{Participantes}

Todas as 7 (sete) profissionais entrevistadas são do sexo feminino, com idades entre 29 e 55 anos, três possuíam formação em Psicologia e quatro em Serviço Social. A experiência em relação à profissão variou 
consideravelmente: entre 6 meses e 25 anos, mas a maioria já atua com o tema da adoção há muitos anos. De modo geral, ao serem contatadas, as profissionais aceitaram participar do estudo; apenas duas profissionais não quiseram participar, preferindo não expor os seus motivos.

Apesar do tempo de experiência de 5 (cinco) dessas profissionais com o tema, nenhuma delas se deparou com situações em que os pretendentes à adoção fossem casais do mesmo gênero. Apesar disso, conhecem e já participaram de outros processos, em que foi possível perceber que a orientação sexual dos principais responsáveis pelas crianças ou adolescentes era homossexual. Três delas apontaram situações envolvendo processos de disputa de guarda, em que um dos pais, após a separação, teria iniciado uma relação homoafetiva e esta questão acabou sendo incluída na pauta das discussões. As outras 4 (quatro) jamais tiveram experiência com essas situações, baseando os relatos, portanto, em suas próprias concepções e conhecimentos técnicos que, ao longo da prática, foram adquirindo sobre o tema. A adoção por sujeitos homossexuais de maneira individual já foi observada por alguns profissionais, mas nenhuma delas apontou peculiaridades nesses casos.

\section{Materiais e instrumentos}

A entrevista com essas profissionais baseou-se em um roteiro semiestruturado, contendo indagações como: a experiência e a compreensão sobre o tema da adoção e da adoção por casais homoafetivos; as principais dificuldades e como se sente para atuar em processos de adoção de modo geral e a percepção ou conhecimento sobre as consequências para o desenvolvimento infantil na adoção realizada por casais homoafetivos. As questões que compuseram o roteiro foram elaboradas pelos próprios pesquisadores, após realizarem a revisão da literatura sobre o tema.

A pesquisa ocorreu em duas cidades localizadas no interior do estado e, a partir das primeiras entrevistas com estes sujeitos, os mesmos puderam indicar outros profissionais que poderiam se enquadrar no perfil da amostra, privilegiando-se sempre profissionais da área de Psicologia e/ou Serviço Social que tivessem experiência relacionada ao tema da adoção. A partir da técnica de "bola de neve", pela qual cada um dos entrevistados indicou outro até alcançar o ponto de "saturação teórica", compôs-se a amostra a ser analisada (BIERNACKI; WALDORF, 1981; FONTANELLA; RICAS; TURATO, 2008; STRAUSS; CORBIN, 1998).

Para a condução da pesquisa, as entrevistas foram gravadas em áudio, com o prévio consentimento dos participantes, e em seguida transcritas integralmente para análise. Para tanto, foi necessária a utilização dos seguintes instrumentos: gravador de MP3, uma folha com o roteiro da entrevista para nortear as pesquisadoras e o termo de consentimento livre e esclarecido assinado pelas profissionais.

\section{Aspectos éticos}

Por tratar-se de um estudo envolvendo seres humanos, a pesquisa foi submetida à avaliação do Comitê de Ética em Pesquisa do Centro Universitário de Araraquara e foi aprovado sob o protocolo ${ }^{\circ}$. 1349/ 11. Com a aprovação, foram realizados contatos com os fóruns e instituições de acolhimentos, onde se prestou os devidos esclarecimentos (através do Termo de Consentimento Livre e Esclarecido), realizando-se a coleta de dados apenas com os profissionais que concordaram em participar do estudo. Outro cuidado ético adotado durante a coleta de dados foi que, diante do reconhecimento de que o assunto tratado poderia mobilizar sentimentos diversos e lembranças das vivências em relação ao tema, as pesquisadoras possuíam condições de oferecer o devido encaminhamento e orientação às entrevistadas que, porventura, apresentassem tais dificuldades.

\section{Local e período de coleta}

A pesquisa foi realizada em duas cidades do interior do Estado de São Paulo, com profissionais da área de Psicologia e Serviço Social, profissões que geralmente compõem a equipe interprofissional das Varas de Infância e Juventude e das instituições de acolhimento. 
As entrevistas foram realizadas primeiramente com as psicólogas e assistentes sociais da equipe interprofissional e, em seguida, com as profissionais da instituição de acolhimento. Tais entrevistas ocorreram durante os meses de abril e maio de 2012 em locais, dias e horários previamente estabelecidos junto aos profissionais, respeitando-se a voluntariedade dos participantes, bem como a disponibilidade dos mesmos.

\section{Procedimentos de montagem do instrumento}

Realizou-se a revisão bibliográfica sobre o tema utilizando-se bases de dados tais como: Scielo, Bireme e Pepsic, cruzando os unitermos: adoção, homossexualidade e adoção homoafetiva. Tais leituras ajudaram a formular o referido roteiro. No intuito de avaliar se este instrumento atendia às necessidades e interesses da pesquisa, primeiramente realizou-se uma entrevista piloto com uma profissional que já teve experiência com estas práticas. Suas informações visaram apenas avaliar a efetividade e a adequação do roteiro e dos dados, assim, não foram incluídas na análise dos resultados desta pesquisa.

\section{Procedimentos de coleta}

As entrevistas foram realizadas individualmente, nas salas onde os próprios profissionais exercem suas atividades, priorizando-se o sigilo e os cuidados para se preservar a qualidade do áudio. Após a apresentação dos objetivos da pesquisa, realização de esclarecimentos gerais e as entrevistadas terem consentido a gravação, foram orientadas a inicialmente se apresentar para que, ao longo da entrevista, e em momento oportuno, as questões que compõem o roteiro pudessem ser introduzidas. As entrevistas tiveram entre uma e duas horas de duração, permitindo ser realizadas em um único encontro com cada participante.

\section{Procedimentos de análise dos dados}

Após a gravação das entrevistas, os participantes foram identificados através de uma numeração (sujeito 1 , sujeito 2 , sujeito 3 , sujeito 4 , sujeito 5 , sujeito 6 e sujeito 7), visando preservar a identidade dos profissionais. Cada entrevista foi lida tantas vezes quanto necessário, a fim de que as respostas às perguntas feitas aos entrevistados fossem as mais completas e claras possíveis. Em seguida, utilizou-se a técnica de análise de conteúdo, definida como uma técnica de tratamento de dados de pesquisa voltada para uma descrição objetiva e sistemática do conteúdo das mensagens (BARDIN, 1977). Esta técnica permite compreender as mensagens, classificando-as em temas que permitam compreender o significado das comunicações. Embora a técnica tenha suas origens na pesquisa quantitativa, busca a interpretação de materiais de caráter qualitativo (CAREGNATO; MUTTI, 2006; GOMES, 2012; MINAYO, 1998).

A partir dessa análise, os relatos foram separados em categorias de respostas, criando-se um arquivo com as respostas de todos os entrevistados em determinada temática ou conteúdo. Foram encontradas as seguintes categorias de respostas: principais dificuldades tema que se relaciona as dificuldades que os profissionais encontram na realização dos procedimentos de adoção; adoção homoafetiva tema que se relaciona à compreensão dos profissionais sobre a adoção realizada por casais homoafetivos; procedimentos técnicos - tema relacionado aos aspectos que os profissionais costumam avaliar junto aos pretendentes à adoção; desenvolvimento infantil e adoção homoafetiva - tema relacionado às considerações dos profissionais a respeito do desenvolvimento infantil em crianças adotadas por casais homoafetivos; e habilidade - tema que se relaciona à compreensão dos profissionais sobre o preparo e a capacidade para lidar com o tema da adoção homoafetiva.

A partir daí, foram feitas inferências, interpretações e hipóteses em relação ao tema investigado, conforme sugerido por Gomes (2012) e Minayo (1998). Foi utilizado o referencial qualitativo de pesquisa, pois este método possibilita a compreensão dos fenômenos sociais que envolvem determinado tema, permitindo entendê-los sob a ótica das pessoas envolvidas diretamente com a questão (CAREGNATO; MUTTI, 
2006; DUARTE, 2002; GOMES, 2012; FONTANELLA; RICAS; TURATO, 2008; STRAUSS; CORBIN, 1998).

Como a amostra que compõe as pesquisas qualitativas geralmente não representa estatisticamente a população estudada, ponderou-se neste estudo não atribuir intensidade, porcentagens ou valores às respostas, tampouco indicar qual dos discursos prevalece. Privilegiou-se apenas descrever e discutir a diversidade de respostas apresentadas pelos participantes, permitindo, assim, explorar as possibilidades de compreensão dos mesmos sobre o tema.

\section{Resultados E discussão}

\section{Caracterização da amostra e relação com o tema da adoção}

Utilizando-se a técnica de "bola de neve" conseguiuse atingir o ponto de saturação teórica com 7 (sete) entrevistas. No que se refere à adoção propriamente dita, indicam satisfação em lidar com este assunto, pois consideram que a medida represente uma alternativa viável para que crianças e adolescentes destituídos do poder familiar possam receber orientação e respaldo através de uma nova configuração familiar.

Tenho uma visão super otimista, é uma das coisas mais gratificantes para trabalhar dentro do Tribunal (...) é muito gratificante perceber que essas crianças conseguiram um lar, uma família e que seria muito difícil conseguir (sujeito 1) - A adoção seria uma alternativa para essas crianças se reestruturarem psicologicamente, terem uma nova família, porque às vezes a criança não tem nem alguém da família para ficar com ela (sujeito 2).

\section{Os procedimentos de adoção e suas dificuldades}

Os profissionais apontaram o trabalho relacionado ao tema da adoção como um campo que exige dedicação, envolvimento e participação da rede de apoio e proteção do município ou região. A maior dificuldade encontrada nesses processos se refere ao contraste entre o perfil desejado pelos pretendentes à adoção e a realidade das crianças e jovens que se encontram em processo de colocação em família substituta. Os discursos sugerem o preconceito, os mitos e a escassez de discussões sobre o tema como um dos possíveis aspectos para esse tipo de dificuldade, principalmente no que se refere à adoção tardia, considerada àquela em que a criança possui idade superior a dois anos.

A dificuldade maior é a preferência dos casais e a idade das crianças (...) porque os casais têm esse ideal de uma criança muito nova e nós temos uma infinidade de crianças maiores (sujeito 5) A maioria dos candidatos querem crianças branquinhas [sic], recém-nascidas e que se pareçam com eles, que não tenham irmãos e tenham boa saúde (sujeito 3 ).

Essas dificuldades, apontadas pelos profissionais, correspondem aos resultados encontrados na literatura e pesquisas sobre o tema (RAMOS, 2009; SOUZA, 2008; SOUZA; MIRANDA, 2007; WEBER, 2001). As adoções consideradas tardias exigem maior atenção, preparo e acompanhamentos mais intensivos das equipes técnicas, uma vez que podem estar presentes questões como: medos, preconceitos e temores em relação a vivências anteriores da criança e influências de sua família de origem, além de receios referentes às sequelas psicológicas devido ao abandono e à institucionalização (JOPPERT; FONTOURA, 2007; SILVA, 2009).

Outras dificuldades apontadas pelos profissionais se referem à necessidade de alguns pretendentes se preparem melhor ou amadurecer a compreensão sobre o tema. Além disso, existem aqueles que, mesmo após a habilitação, costumam ficar ansiosos e impacientes em relação à espera. Weber (2004) enfatiza a necessidade da preparação, uma vez que são raras as pessoas que se organizam para ter um filho, seja ele adotivo ou não. Preparar-se para os autores significa refletir sobre as próprias motivações, riscos, expectativas, desejos ou medos; constitui-se em tornar 
consciente os limites e as possibilidades de si mesmo, do outro e do mundo.

Outro ponto é quando você dá um parecer desfavorável (...) teve caso da gente achar que o casal precisava amadurecer mais algumas coisas, então eu pedi uma nova avaliação em seis meses. Os casais reagem mal, é como se estivesse desqualificando, eles não entendem que é uma coisa específica para aquela situação, eles tomam como uma coisa pessoal, então isso é um pouco complicado de você os fazer entender (sujeito 4) - A dificuldade é a falta de paciência das pessoas que se inscrevem. Tem as cobranças, eles ficam ligando, exigindo, cobrando, como se dependesse da gente, então é uma dificuldade (sujeito 6).

Nesse sentido, mostra-se importante e indicado realizar grupos que estimulem a reflexão e promovam o aprendizado, podendo-se utilizar estratégias de encontros multifamiliares, onde cada família ensina e aprende com a outra e com os profissionais da equipe técnica, que por sua vez também aprendem com estas famílias (CAMPOS; COSTA, 2004; COSTA; CAMPOS, 2003; SILVA FILHO, 2009; SILVA, 2009; SOUZA, 2008). Essas necessidades foram contempladas e passaram a se tornar exigências por meio da Lei 12.010/2009, que incluiu na redação original do artigo 50 do Estatuto da Criança e do Adolescente (Lei 8.069/1990), em seu parágrafo $3^{\circ}$, a necessidade da inscrição ser precedida de um período de preparação psicossocial e jurídica orientada pela equipe técnica da Justiça da Infância e Juventude.

Com a introdução dessas novas exigências, regulamentadas pela lei de convivência familiar (Lei 12.010/2009), algumas profissionais apontam já observar mudanças não somente no perfil das crianças pretendidas, como também no preparo dessas famílias para acolher e lidar com o tema da adoção.

Depois que a gente fez os cursos pros pretendentes, vários casais vieram conversar sobre a possibilidade de modificar o perfil da criança, então eu acho que se abriu um espaço para se pensar de outra forma (...) a gente percebeu essa mudança aqui na nossa comarca (sujeito 1).

\section{Adoção por casais homoafetivos e o desenvolvimento psicossocial de crianças adotadas}

A opinião dos profissionais sobre esta modalidade de adoção se mostrou diversificada. Os discursos variam desde aqueles que se opõem a esta configuração, passando pelos que se mostram indecisos ou neutros, preocupados principalmente com o desenvolvimento da criança ou adolescente até aqueles que são favoráveis a este tipo de adoção, devendose, portanto, dirigir o enfoque da avaliação para outros aspectos além da orientação sexual. Para estes últimos, trata-se de uma condição que não pode ser vista com preconceito, devendo-se analisá-la com os mesmos critérios utilizados em outras formas de adoção.

Particularmente, um homem e uma mulher é quem cria os filhos. Porque eu não sei se conseguiria trabalhar em um caso assim, passaria a bola pra frente (sujeito 6) - Eu não sou contra, eu só penso como vai ser o desenvolvimento dessa criança, sem um papel masculino e feminino, eu acho que vai acarretar algum problema (sujeito 2) - Eu particularmente penso que o casal homoafetivo pode adotar, eu acho que desde que você observe todas essas características, esses critérios, eu acho que você faz uma avaliação da mesma forma, eu acho que isso não pode ser impeditivo para eles (...) acho que deve ser encarado com normalidade (sujeito 4).

Os aspectos relacionados ao desenvolvimento emocional das crianças é um tema que gera muitos questionamentos às entrevistadas. Como a experiência delas com essa configuração familiar tem sido rara, baseiam suas opiniões nas pesquisas e estudos sobre o tema, e acreditam que observações mais amplas 
sobre o assunto ainda sejam necessárias. De qualquer forma, relacionam a possibilidade de haver consequências para o desenvolvimento a dois aspectos: família e sociedade. Consideram que o modo pelo qual as famílias conduzirão o tema é de fundamental importância e destacam os prejuízos que os preconceitos existentes na sociedade poderão acarretar na educação dessas crianças.

Os estudos têm demonstrado que as crianças apresentam o mesmo desenvolvimento que as crianças criadas por casais heterossexuais (...) os estudos são muito recentes, nós temos poucos dados, é um conhecimento que eu acho que ainda está sendo construído (sujeito 4) -É difícil a gente falar, afirmar que vai dar problema ou que não vai dar, acho que tudo é possível, acho que depende como é feito, como é trabalhado (sujeito 3) - Eu acho que pra criança é mais difícil, ela precisa ser muito bem preparada, porque é uma sociedade preconceituosa que a gente tem ainda (sujeito 6).

A questão relacionada à ausência de modelos masculinos e femininos no desenvolvimento infantil também gera dúvidas a algumas profissionais. Futino e Martins (2006) apontaram a tendência a se construir esse tipo de raciocínio, que para as autoras é equivocado, pois as atribuições de gênero em nossa sociedade não são pré-definidas ou geneticamente determinadas, mas sim socialmente construídas. "Eu penso que sim, que vai influenciar o desenvolvimento da criança sim, ela não vai ter um papel feminino e um masculino, por mais que o casal tente" (sujeito 2).

Independente do posicionamento, o tema, segundo as entrevistadas, costuma ser polêmico. Se a questão referente à adoção, de modo geral, já é cercada de preconceitos e mitos, a possibilidade de se configurar uma relação familiar através da adoção por casais homoafetivos torna a discussão ainda mais complexa. Apontam o preconceito da sociedade em relação à orientação sexual dos indivíduos e a capacidade dos mesmos em exercer as funções parentais como um dos principais obstáculos, gerando divergências sobre o tema. De qualquer forma, acreditam que a discussão e as experiências ainda sejam recentes e, portanto, ainda deverão aprender a lidar com ela.

É complicado, é polêmico (sujeito 3) - Eu acho que ainda existe um preconceito, eu acho que na nossa sociedade, culturalmente, tem esse preconceito (sujeito 1) - Eu acho que é uma situação nova, que a gente está tendo que aprender a lidar agora (sujeito 4).

A escassez de literatura e de pesquisas sobre o tema talvez reflita as divergências apresentadas nos discursos acima. De qualquer modo, tais questões devem ser suficientemente elaboradas para as crianças, pois os filhos de pais homossexuais terão que superar muitas adversidades e obstáculos para atingir a plenitude de seu desenvolvimento, exigindo-se esforços e apoio da equipe técnica. Deve-se esclarecer que os problemas e dificuldades que poderão surgir não estão relacionados à orientação sexual do(s) adotante(s), mas sim às "reações hipócritas, preconceituosas e discriminatórias da nossa sociedade, considerada 'normal"' (SILVA, 2009, p.224).

A resistência em relação à adoção homoafetiva geralmente se baseia na argumentação de que essas relações são promíscuas e não oferecem condições saudáveis ao desenvolvimento por interferir na orientação sexual da criança. Para Silva (2009), tais argumentos se mostram infundados e preconceituosos, porque as crianças precisam ser desejadas e não suprir as carências afetivas dos pais; precisam ser reconhecidas para se sentirem incluídas no grupo familiar e isso não depende da orientação sexual dos pais, além disso, as famílias heteroparentais podem ser tão nocivas, prejudiciais e destrutivas ou ainda mais graves que as homoparentais (ARAÚJO et al. 2007; FUTINO; MARTINS, 2006).

Eu acho que depende, tem casal hétero que adota e pode não dá certo (...) eu acho que devemos ver se o ambiente foi bem estruturado para a 
criança (...) é preferível que ela viva em um ambiente que tenha estrutura, independentemente se o casal é homossexual ou não, porém, o tema é polêmico (sujeito 3).

\section{Preparo para lidar com o tema da adoção homoafetiva}

Se a adoção, de maneira geral, indica dificuldades mais relacionadas à natureza dos processos e às demandas dos pretendentes, quando o tema se refere especificamente à adoção por casais homoafetivos, os obstáculos parecem se concentrar mais nas questões pessoais das entrevistadas. Os discursos apontam a necessidade de buscar maior informação, explorar melhor o assunto, assinalando a necessidade de supervisão para esses casos. De modo geral, admitem a necessidade de vencer preconceitos e opiniões pessoais sobre o tema, para que esses aspectos não prejudiquem a avaliação e $o$ acompanhamento, indicando até mesmo a possibilidade de se abdicar desses processos ou encaminhá-los para profissionais que estejam melhor preparados para lidar com o assunto:

Acho que temos que estudar pra estar preparada para essa nova situação (...) eu acho que a gente tem que se avaliar, buscar novos caminhos, se preparar, aprender a lidar com essa situação pra ir vivendo e aprendendo como vão ser as coisas (sujeito 7) - É uma situação que eu vou querer olhar com bastante calma, para me cercar de que eu estou fazendo uma avaliação despida de qualquer preconceito (...) eu acho que vai ser uma avaliação que vai me deixar um pouco mais preocupada, mais atenta (sujeito 4) - Infelizmente não me considero preparada para lidar com esse tipo de adoção (...) Se chegar algum caso de adoção homoafetiva, eu vou trocar com alguém, não dou conta, eu tenho minha religião, então isso acaba me influenciando, pra mim isso é difícil, então pra não fazer mal feito, eu vou passar pra outra pessoa pra que eu não influencie (sujeito 6).

A literatura sobre a preparação de casais e pessoas que pretendem adotar é extensa, existem diversos sites e associações que produzem e publicam extensivo material sobre dúvidas a respeito do tema. O mesmo, entretanto, não se observa em relação aos profissionais que acompanhame atuam diretamente nos processos de adoção por casais homoafetivos. Na ausência de suporte e de supervisão, muitos processos podem ficar a mercê das opiniões e aspectos morais dos próprios técnicos. Campos e Costa (2004), ao realizarem um estudo qualitativo com técnicos da equipe interprofissional de uma determinada Vara de Infância e Juventude, observaram a ansiedade relacionada à realização do estudo psicossocial não só para as famílias postulantes, como para os técnicos envolvidos. Para estes últimos, a responsabilidade pelo "acerto" da adoção, assim como a possibilidade de sua função dar margens a abusos de poder, devido à subjetividade que envolve o processo de avaliação, são variáveis que podem gerar desconfortos a todos os envolvidos.

Weber (2004) destaca a relevância dos profissionais trabalharem de forma preventiva, atuando desde os primeiros contatos com os pretendentes, assim como durante o estágio de convivência e mesmo após a adoção, como orientadores e auxiliadores e não como peritos ou avaliadores:

Anteriormente, a avaliação de candidatos consistia apenas em critérios de seleção de moradia, ingresso e composição familiar. Agora a tendência marca a necessidade de se estabelecer um processo de assessoria constante para as famílias adotivas, tanto antes quanto depois da colocação da criança em família substituta. Em vez de ter o objetivo de encontrar pais ideais, a equipe técnica dos Juizados da Infância e Juventude deve saber recrutar candidatos para o grande número de crianças que precisam de uma família e ajudar os postulantes a se tornarem pais capazes de satisfazer as necessidades de um filho adotivo. (WEBER, 2004, p.129)

\section{Conclusões}

O presente estudo permitiu explorar a compreensão 
dos profissionais que atuam em processos de adoção, podendo se verificar que, tanto para as entrevistadas quanto na literatura, o tema da adoção, por si só, costuma gerar discussões e está cercado de mitos e preconceitos. Nesse contexto, a questão relacionada à adoção por casais homoafetivos parece intensificar ainda mais as altercações a respeito, uma vez que, além das dúvidas sobre a capacidade destes indivíduos em exercer as funções parentais, muito também se questiona acerca do desenvolvimento emocional das crianças e adolescentes adotados por esses casais, tornando o tema da adoção ainda mais cercado de preconceitos e resistências.

A história e a literatura a respeito do tema demonstram quanto as configurações familiares, ao longo dos anos, estiveram submetidas às legislações ao mesmo tempo em que estas precisaram rever determinadas normas e se atentar às transformações sociais. Aluta daqueles que se sentiam excluídos ou sofriam preconceito por sua condição não ser regulamentada pelo Estado parece sempre ter sido acompanhada de uma resistência inicial que, aos poucos e a partir de mudanças na legislação, foi sendo melhor acolhida pela sociedade em geral, ainda que alguns grupos expressem certa contrariedade. Aadoção é um exemplo dessas transformações e a adoção por casais homoafetivos pode ser entendida como mais um capítulo ou aspecto a ser assimilado.

As profissionais que atuam diretamente nesses processos se sentem satisfeitas em se envolver com essas tarefas e se mostram preparadas para lidar com a adoção, apesar de todas as dificuldades que cercam o tema, como: o contraste dos perfis entre pretendentes e crianças/adolescentes, assim como o despreparo de algumas famílias que procuram a adoção. Já no que se refere à adoção por casais homoafetivos, nenhuma das profissionais analisadas se deparou com a situação, e apresentaram opiniões distintas a respeito do assunto. Verifica-se que as dificuldades em torno do tema para essas profissionais se deparam-se também com questões pessoais, não sendo possível determinar, apenas pela análise de conteúdo das mensagens, se a diversidade de compreensões a respeito do tema está ou não relacionada ao tempo de experiência ou à área de formação.

Ao mesmo tempo em que reconhecem a complexidade do assunto, as profissionais atribuem as polêmicas que envolvem o tema aos preconceitos e às próprias dificuldades da sociedade em lidar com essas questões. Estas considerações demonstram que, mesmo possuindo formação para atuar com os conflitos e demandas populacionais, os profissionais ligados a essas atividades não estão isentos das representações e considerações que a sociedade faz em relação ao tema, uma vez que também estão inseridos e fazem parte do sistema. O presente estudo possibilitou dar voz a esses profissionais, indicando que os mesmos sentem falta de um debate mais amplo sobre o tema, tanto nas comunidades científicas como na sociedade em geral, haja vista que esta última, muitas vezes, deposita nesses profissionais a esperança de ver atendida as suas considerações a respeito do tema, sejam elas a favor ou contra.

De qualquer forma, as profissionais admitem a necessidade de refletir e se preparar melhor para lidar com essas questões, reconhecendo, portanto a necessidade de observar com maior atenção, assim como buscar maiores informações a respeito do tema. Pesquisas e textos sobre o assunto, apesar de escassos e ainda muito recentes, têm sido a principal fonte de informação e referência destes profissionais, daí a necessidade de outros estudos sobre adoção por casais homoafetivos, visando ampliar e oferecer respaldo não só a aos profissionais, mas à sociedade em geral.

No que se refere ao modo como a sociedade lida com essas questões, verifica-se a necessidade de ampliar o debate e as discussões a respeito, haja vista que a falta de informação e o fato da legislação que regulamenta as uniões entre homossexuais ainda ser recente também contribui para a construção de fantasias e concepções equivocadas sobre o tema. $\mathrm{O}$ novo paradigma envolvendo o recrutamento de pretendentes à adoção, que enfatiza a preparação em vez da classificação, também pode contribuir para esclarecer melhor a sociedade, desconstruindo, assim, mitos e estereótipos que ainda cercam o tema. 
Destarte, como muitos profissionais deste estudo e da literatura apontaram, os acompanhamentos desses processos devem direcionar seus esforços para avaliar a capacidade das famílias em exercer as funções parentais, em vez de enfocar a sexualidade dos responsáveis.

Por fim, é válido assinalar que, embora a legislação que regulamenta essas uniões ainda seja recente, o mesmo não se pode apontar em relação à homossexualidade, a qual, desde o ano de 1990, deixou de ser considerada pela Organização Mundial de Saúde (OMS) como um possível transtorno ou diagnóstico em saúde mental, passando a ser considerada como mais uma entre outras possibilidades de orientação e expressão da sexualidade dos indivíduos. Se por um lado a legislação procura atender aos direitos desses indivíduos, por outro ainda se observa certa resistência de alguns setores em deixar de considerar a homossexualidade como um problema de saúde mental ou desvio de conduta, tornando, portanto, a discussão em relação à adoção ainda mais requintada.

Este estudo, entretanto, se limitou apenas a explorar um pequeno grupo de indivíduos que compõem o universo de profissionais que atuam nos processos de adoção, não sendo possível, portanto, generalizar tais considerações. Além disso, outras pesquisas e estudos que possam explorar a compreensão da população e outros agentes envolvidos no tema, como juízes e operadores de direito, poderão ampliar a exploração do tema. Embora a presente pesquisa não permita realizar considerações mais abrangentes, pretende, através desta exploração, apresentar subsídios para uma discussão inicial sobre a atuação de profissionais em processo de adoção por casais homoafetivos.

\section{Referências}

AMAZONAS, M. C. L. A.; DAMASCENO, P. R.; TERTO, L. M. S.; SILVA, R. R. Arranjos familiares de crianças de camadas populares. Psicologia em Estudo, Maringá, v.8, n.esp, p. 11-20. 2003. Disponível em: <http://www.scielo.br/pdf/pe/v8nspe/ v8nesa03.pdf>. Acesso em: 07 jul. 2014.

ARAÚJO, L. F.; OLIVEIRA, J. S. C.; SOUSA, V. C.; CASTANHA, A. R. Adoção de crianças por casais homoafetivos: um estudo comparativo entre universitários de Direito e de Psicologia. Psicologia e Sociedade, Porto Alegre, v.19, n.2, p. 95-102, mai/ago. 2007. Disponível em: <http:// www.scielo.br/pdf/psoc/v19n2/a13v19n2.pdf >. Acesso em: 22 set. 2011.

\section{BARDIN, L. Análise de Conteúdo. Lisboa, Edições 70, 1977. 223 p.}

\section{BIERNACKI, P.; WALDORF, D. Snowball} sampling: problems and techniques of chain referral sampling. Sociological Methods and Research, London, v. 10, n.2, p. 141-163. 1981.

\section{BRASIL. Constituição da República Federativa} do Brasil. Brasília: Senado, 1988. Disponível em: <http://www.planalto.gov.br/ccivil_03/constituicao/ constitui\%C3\% A7ao.htm>. Acesso em: 06 outubro 2011.

BRASIL. Estatuto da Criança e do Adolescente. Lei Federal 8.069 de 13 de julho de 1990. República Federativa do Brasil: Poder Legislativo, 1990. Disponívelem: <http://www.planalto.gov.br/ ccivil/Leis/L8069.htm>. Acesso em: 05 out. 2011.

BRASIL. Lei n. 12.010 de 3 de agosto de 2009. Dispõe sobre adoção; altera as Leis nos 8.069, de 13 de julho de 1990 - Estatuto da Criança e do Adolescente, 8.560, de 29 de dezembro de 1992; revoga dispositivos da Lei no 10.406, de 10 de janeiro de 2002 - Código Civil, e da Consolidação das Leis do Trabalho - CLT, aprovada pelo DecretoLei no 5.452, de $1^{\circ}$ de maio de 1943; e dá outras providências. República Federativa do Brasil: Poder Legislativo, DF, 3 agosto 2009. Disponívelem: <http:/ /www.planalto.gov.br/ccivil_03/_ato2007-2010/ 2009/lei/112010.htm>. Acesso em: 11 jan. 2012. 
CAMPOS, N. M. V.; COSTA, L. F. A subjetividade presente no estudo psicossocial da adoção. Psicologia: reflexão e crítica. Porto Alegre, v. 17, n.1, p. 95-104. 2004. Disponível em: <http:// www.scielo.br/pdf/prc/v17n1/22309.pdf>. Acesso em: 23 abril 2012.

CAREGNATO, R. C. A.; MUTTI, R. Pesquisa qualitativa: análise de discurso versus análise de conteúdo. Texto Contexto Enferm., Florianópolis, v. 15 , n. 4, p. 679-84, out/ dez. 2006. Disponível em: <http://www.scielo.br/pdf/tce/v15n4/ v15n4a17.pdf $>$. Acesso em: 3 maio 2012.

\section{CHEMIN, S. A.; SESARINO, S. V. R. Adoção e} Homossexualidade: a civilização e seu mal-estar. In: CARVALHO, M. C. N.; MIRANDA, V. R. (Orgs.) Psicologia Jurídica: Temas de Aplicação I. Curitiba: Juruá, 2007. p 117-134.

\section{CONSELHO NACIONAL DE JUSTIÇA.}

Resolução $n^{\circ} 175$ de 14 de maio de 2013. Ministro Joaquim Barbosa. Resolução n ${ }^{\mathbf{0} 175}$ : Dispõe sobre a habilitação, celebração de casamento civil, ou de conversão de união estável em casamento, entre pessoas de mesmo sexo, Brasília, 2013.

COSTA, L. F.; CAMPOS, N. M. V. A avaliação psicossocial no contexto da adoção: vivências das famílias adotantes. Psicologia Teoria e Pesquisa. Brasília, v. 19, n. 3, p. 221-230. 2003. Disponível em: <http://www.scielo.br/pdf/ptp/v19n3/ a04v19n3.pdf $>$. Acesso em: 24 jan. 2012.

COSTA, T. M. M. L. Adoção por pares homoafetivos: uma abordagem jurídica e psicológica. Faculdade de Ciências Jurídicas e Sociais Vianna Júnior, 2003. Disponívelem: <http:// intranet.viannajr.edu.br/revista/dir/doc/ art_10005.pdf>. Acesso em: 13 out. 2011.

DUARTE, R. Pesquisa qualitativa: reflexões sobre o trabalho de campo. Cadernos de Pesquisa, São
Paulo, n. 115, p. 139-154, mar. 2002. Disponível em: <http://www.scielo.br/pdf/cp/n115/ a05n115.pdf $>$. Acesso em: 26 set. 2011.

FONTANELLA, B. J. B.; RICAS, J.; TURATO, E. R. Amostragem por saturação em pesquisas qualitativas em saúde: contribuições teóricas. Cad. Saúde Pública, Rio de Janeiro, v. 24, n. 1, p.17-27, jan. 2008. Disponível em: <http://www.scielo.br/pdf/ csp/v24n1/02.pdf>. Acesso em: 25 abril 2012.

FUTINO, R. S.; MARTINS, S. Adoção por homossexuais: uma nova configuração familiar sob os olhares da psicologia e do direito. Aletheia, Canoas, n. 24, p. 149-159, jul/dez. 2006. Disponívelem: < http://pepsic.bvsalud.org/pdf/ aletheia/n24/n24a14.pdf>. Acesso em: 26 set. 2011.

GOMES, R. Análise e interpretação de dados de pesquisa qualitativa. In: MINAYO, M. C. S. (Org.) Pesquisa Social: teoria, método e criatividade. Rio de Janeiro: Vozes, p 79-108, 2012. 108 p.

JOPPERT, D. M. R.; FONTOURA, T. Adoção tardia: a importância do preparo psicológico de candidatos a pais e filhos adotivos. In: CARVALHO, M. C. N.; MIRANDA, V. R. (Orgs.) Psicologia Jurídica: Temas de Aplicação I. Curitiba: Juruá, 2007. p 93-116.

MINAYO, M. C. S. O Desafio do Conhecimento: pesquisa qualitativa em saúde. São Paulo, Hucitec, ABRASCO, 1998. 269 p.

PAULO, B. M. Família: uma relação socioafetiva. In: PAULO, B. M. (Coord.) Psicologia na Prática Jurídica: A criança em foco. Rio de Janeiro: Impetus, 2009. p. 27-38.

PRATTA, E. M. M.; SANTOS, M. A. Família e adolescência: a influência do contexto familiar no desenvolvimento psicológico de seus membros. Psicologia em Estudo. Maringá, v.12, n. 2, p. 247- 
256, mai/ago. 2007. Disponível em: <http:// www.scielo.br/pdf/pe/v12n2/v12n2a05.pdf $>$. Acesso em: 23 outubro 2011.

RAMOS, P. A. Acolhimento institucional de crianças e suas consequências. In: PAULO, B. M. (Coord.) Psicologia na Prática Jurídica: A criança em foco. Rio de Janeiro: Impetus, 2009. p 79-90.

SALOMÉ, G. M.; ESPÓSITO, V. H. C.; MORAES, A. L. H. O significado de família para casais homossexuais. Revista brasileira de enfermagem, Brasília, v. 60, n. 5, p. 559-563, set/ out. 2007. Disponível em: <http://www.scielo.br/pdf/ reben/v60n5/v60n5a14.pdf>. Acesso em: 21 set. 2011.

SCHETTINI, S. S. M.; AMAZONAS, M. C. L. A.; DIAS, C. M. S. B. Famílias adotivas: identidade e diferença. Psicologia em estudo, Maringá, v. 11, n. 2, p. 285-293, mai/ago. 2006. Disponível em: <http://www.scielo.br/pdf/pe/v11n2/v11n2a06.pdf>. Acesso em: 19 outubro 2011.

SILVAFILHO, A. M. Adoção: regime jurídico, requisitos, efeitos, inexistência, anulação. 2. ed. São Paulo: Ed. Revista dos Tribunais, 2009. 333 p.

SILVA, D. M. P. Psicologia Jurídica no Processo Civil Brasileiro: a interface da psicologia com o direito nas questões de família e infância. Rio de
Janeiro: Forense, 2009. 446 p.

SOUZA, H. P. Adoção: exercício da fertilidade afetiva. São Paulo: Paulinas, 2008. 224 p.

SOUZA, R. P.; MIRANDA, V. R. Adoção: considerações histórico-sociais, psicológicas e jurídicas. In: CARVALHO, M. C. N.; MIRANDA, V. R. (Orgs.) Psicologia Jurídica: Temas de Aplicação I. Curitiba: Juruá, 2007. p 79-92.

STRAUSS, A. S.; CORBIN, J. Basics of qualitative research: Techniques and procedures for developing grounded theory. $2^{\mathrm{a}}$ ed., London, Sage Publications Editor, 1998. 336 p.

SUPREMO TRIBUNAL FEDERAL. Pagina 2 do Ofício no 81/P-MC, de 9 de maio de 2001. Disponível em: <http://direitohomoafetivo.com.br/ anexos/normatizacao/of\%E Dcio_stf.pdf $>$. Acesso em: 15 jun. 012 .

WEBER, L. N. D. O psicólogo e as práticas de adoção. In: GONÇALVES, H. S.; BRANDÃO, E. P. (Orgs.). Psicologia Jurídica no Brasil. Rio de Janeiro: NAU Ed, 2004. p 99-140.

WEBER, L. N. D. Pais e filhos por adoção no Brasil: características, expectativas e sentimentos. Curitiba: Juruá, 2001. 283 p. v.1.

RECEBIDO EM 17/7/2013

ACEITO EM 22/5/2014 